\title{
Los libros-registro de esclavos, el sistema de licencias y la trata con Hispanoamérica en el siglo XVI: análisis y aspectos metodológicos a través del caso vasco*
}

\author{
The Libros-Registro de Esclavos, the Sistema de Licencias \\ and the Slave Trade with the Spanish America \\ in the $16^{\text {th }}$ Century: Analysis and Methodological Aspects \\ through the Basque Case
}

\author{
Javier Ortiz Arza \\ https://orcid.org/0000-0002-1410-1879 \\ Universidad del País Vasco, Álava, España
}

En este trabajo analizamos la estructura de los libros-registro de esclavos conservados en el Archivo General de Indias y su potencial como fuente de investigación para el estudio de la trata con las Indias de Castilla en el siglo XVI. Siguiendo el hilo conductor que los propios libros señalan, identificaremos las fases del sistema de licencias, los diferentes perfiles de los intervinientes y las pautas de actuación asociadas a cada uno de ellos, siempre tomando como telón de fondo el caso de la comunidad vasca.

Palabras Clave: Trata de Esclavos; Indias; Metodología y Fuentes; Vascos; Siglo XVI.

In this paper we analyze the structure of the Libros-Registro de Esclavos stored in the Archivo General de Indias and its potential as a research source for the study of the slave trade with the Indies in the $16^{\text {th }}$ century. Following the unifying thread that the books point out, we will identify the stages of the system, the participants' profile and the behavioural patterns of each of them, taking always into account the background of the Basque case.

Keywords: Slave Trade; Indies; Methodology and Sources; Basques; $16^{\text {th }}$ Century.

Copyright: (C) 2020 CSIC. Este es un artículo de acceso abierto distribuido bajo los términos de la licencia de uso y distribución Creative Commons Reconocimiento 4.0 Internacional (CC BY 4.0).

* El presente artículo se ha realizado en el marco del proyecto I+D «Mercados y Tratas de Esclavos en el Atlántico Ibérico del siglo XVI» (HAR2016-78056-P) concedido por el Ministerio de Economía y Competitividad. 


\section{Introducción y relevancia del caso vasco}

Los libros-registro de esclavos conservados en el Archivo General de Indias son fuentes conocidas y de fácil acceso. ${ }^{1}$ Constituyen, a grandes rasgos, el reflejo documental directo del entramado administrativo que vertebró el primer tráfico esclavista con las Indias de Castilla. Por ello, son citados con cierta frecuencia por los investigadores, pero hasta el momento no han sido objeto del tratamiento que por su importancia como documento histórico merecen. Su escaso aprovechamiento puede explicar en parte que la trata española del siglo XVI sea la gran desconocida dentro de nuestro ámbito de estudio, siempre en clara desventaja con respecto a otros momentos históricos. ${ }^{2}$ Por otra parte, los trabajos sobre el sistema de licencias o sobre metodología y análisis de fuentes tampoco han supuesto ninguna prioridad para la historiografía sobre la esclavitud en España. ${ }^{3}$

Afortunadamente esta situación ha comenzado a cambiar en los últimos años. Algunos de los avances más significativos se llevan a cabo en el departamento de Historia Moderna de la Universidad de Sevilla. Rafael Pérez García propone tres fuentes principales para una aproximación al estudio de las licencias: ${ }^{4}$ los propios otorgamientos dispersos en distintos cedularios y recopilaciones diplomáticas, la documentación fiscal del almojarifazgo de esclavos ${ }^{5}$ y los propios libros-registro. La trata del siglo XVI también ha merecido la atención reciente de la historiografía anglosajona, habitualmente orientada hacia cronologías más tardías, destacando, en este sentido, las nuevas aportaciones de David Wheat y Marc Eagle,

1 Archivo General de Indias, Sevilla (AGI), Contratación, 5760, 5761 y 5762. Cada legajo se divide a su vez en varios libros. El título atribuido por el archivo es el siguiente: «Libros de asientos de licencias para esclavos». Si acudimos a la propia documentación (AGI, Contratación, 5761, 1. 5), podemos leer «libro donde tiene la quenta y razón de las liçençias de esclavos que Su Magestad haze merced a personas particulares para pasar a las Indias». O el más escueto «libro de esclavos» (AGI, Contratación, 5762, 1. 9). Su contenido, sin embargo, es mucho más amplio, ya que incluyen las valiosas cuentas de registros a Hispanoamérica. A lo largo del trabajo, por tanto, nos referiremos a ellos como «libros-registro de esclavos» o «libros de Contratación».

2 Para el período de asientos del siglo XVII contamos con la obra de referencia de Vila Vilar, 2014 [1977]. Borucki, Eltis y Wheat $(2015,437)$ también abordan esta cronología y sitúan el pico máximo de las exportaciones esclavistas castellanas entre 1581 y 1640.

3 Véanse a este respecto los estudios de García Fuentes, 1982; Vila Vilar, 1985; Donoso Anes, 2001; Pérez García, 2015.

4 Pérez García, 2015, 833.

5 Es el método empleado por Pérez García y Fernández Chaves (2009, 610), quienes recogen también los datos aportados por Modesto Ulloa para el período 1544-1569, sacados de la misma fuente. 
que ponen el acento en las características de los transportes esclavistas y en el discurrir posterior a la partida de los navíos. Ambos autores valoran este temprano tráfico de esclavos no como una actividad preliminar, exploratoria o de poco interés, sino como un elemento fundamental en la articulación del espacio atlántico, señalando también la necesidad de poner en relación los diferentes tipos documentales generados a lo largo de todas las etapas del proceso, ${ }^{6}$ que engloba momentos tan lejanos entre sí como la concesión de las licencias, la llegada de los esclavos a los puertos de las Indias o la entrega del producto de su venta a los cargadores de Sevilla.

Este artículo se complementa con algunos de los aspectos mencionados y con ese creciente interés por los orígenes de la trata. En primer lugar, busca documentar el proceso anterior a la carga y transporte de los esclavos, señalando las líneas maestras del conocido como sistema de licencias, del cual beberá, en parte, el posterior período de asientos. En esta etapa, no hay que olvidarlo, los esclavos son todavía cifras anotadas en un libro de gestión, ya que la mayoría se encuentran en sus lugares de origen y desconocen que su futuro está siendo sellado en una ciudad castellana durante el transcurso de un largo entramado burocrático. Entendemos la trata inicial abordada en estas páginas como una compleja maquinaria comercial y administrativa organizada en distintas fases (concesión de licencias, mercado secundario y registro) que generan a su vez diferentes perfiles (beneficiarios, distribuidores, cargadores de esclavos, etcétera), siempre en consonancia con los intereses de cada persona o con sus cualidades profesionales.

Por último, a la espera de un estudio general centrado en el siglo XVI, creemos que pueden resultar útiles las aproximaciones parciales a través de comunidades concretas. De esta forma, algunos de los temas planteados se analizarán tomando como modelo el caso vasco: un colectivo de gran tradición comercial y marítima, con una notable presencia en el mundo socioeconómico hispalense y muy activo en la trata de esclavos gracias a figuras como Juan de Urrutia, Francisco de Zavala o Pedro de Morga. Estos enfoques dirigidos a grandes «naciones» mercantiles pueden ayudar a señalar una serie de pautas y características que con el tiempo se demuestren representativas de dinámicas más generales, ${ }^{7}$ todo ello a la vez que

6 Eagle, 2019. Eagle y Wheat, 2020.

7 Actualmente se encuentra abierta una línea de trabajo sobre el caso portugués, que va desde lo general (Fernández Chaves y Pérez García, 2011) hasta lo particular de figuras mercantiles concretas, por ejemplo, Bento Váez (Fernández Chaves, 2018). 
nos descubren los rasgos más particulares de cada comunidad. En el caso vasco, por ejemplo, llama la atención su constante presencia en los órganos rectores de la Monarquía, como el Consejo de Indias o la Contratación, lo que les pudo facilitar el acceso a las concesiones; su afinidad por las actividades financieras y el negocio especulador de las licencias, o su tendencia a estrechar lazos de colaboración con individuos de su mismo grupo, por ejemplo en los acuerdos entre cargadores y navegantes para el transporte de los esclavos.

\section{Los libros-registro de esclavos: contenido y valor como fuente histórica}

Los principales bloques de información incluidos en nuestra fuente son los siguientes:

- Traslados de las cédulas reales mediante las que se favorecía a determinadas instituciones o particulares con un número variable de licencias para «pasar» esclavos a las Indias.

- Información adicional sobre los aspectos jurídicos, económicos o de cualquier otra índole que hubieran motivado dichas concesiones, como un pleito, una permuta por deudas de juros, etcétera.

- Alertas sobre los cambios de titularidad de las licencias y su circulación por los mercados de Sevilla.

- Cuentas de registros — envíos a Indias — vinculados a cada cédula o lote de licencias.

- Datos referentes al transporte de los esclavos, fundamentalmente el nombre del maestre con el que se han negociado los fletes. De forma irregular, pueden aparecer también el lugar de carga, el destino del navío, algunas características del mismo, etcétera.

Como señala Pérez García, un aspecto fundamental a la hora de valorar esta primera trata con las Indias consiste en averiguar hasta qué punto las licencias concedidas se tradujeron en esclavos registrados. La función principal de los libros de Contratación era precisamente vigilar la circulación de las licencias y sobre todo su proceso de canjeo por registros, siempre con el fin de evitar que pasaran más esclavos de los autorizados en cada cédula. Creemos que un análisis exhaustivo de la fuente permitirá responder a este interrogante; por el momento, Pérez García anticipa que la mayor parte 
de las licencias fueron empleadas y agotadas, hipótesis que, desde nuestra experiencia concreta con el caso vasco, compartimos plenamente. ${ }^{8}$ Asimismo, al tratarse de instrumentos de control administrativo, es muy posible que los libros recojan, si no todas, sí gran parte de las cédulas otorgadas por el monarca, de modo que un vaciado de datos puede ayudar a cuantificar el número de esclavos introducidos en las Indias durante el siglo XVI. Esta fórmula tampoco deja de plantear incógnitas, por ejemplo saber cuántos de los esclavos registrados llegaron realmente a destino. Sin embargo, como veremos más adelante, los libros también recogen información sobre casos conflictivos por problemas de abastecimiento o mortalidad, los cuales, habitualmente, terminaban generando una cascada de documentación en forma de pleitos y nuevas solicitudes de licencias que es posible rastrear y analizar. ${ }^{9}$

Por otro lado, a la hora de abordar un proceso tan complejo y extendido en el tiempo, el investigador suele tropezar con el problema de la dispersión de los datos. Frente a esto, nuestra fuente tiene la virtud de concentrar la información en unos legajos específicos y bien localizados. Su estructura orgánica, seriada y cronológica, permite obtener una visión panorámica de la faceta más abstracta e inmaterial de la trata, que arranca meses o incluso años antes de que los acuerdos en papel se traduzcan en navíos, esclavos y rutas concretas. Partiendo de esta base, nuestra propuesta consistirá en identificar las diferentes etapas del sistema siguiendo el hilo conductor que los propios libros indican. Asimismo, señalaremos los diferentes perfiles de las personas intervinientes y, a través de un vaciado de datos parcial centrado en la comunidad vasca, analizaremos la práctica comercial de estos individuos en lo tocante a las licencias y los registros de esclavos. Del mismo modo, precisaremos algunos términos o conceptos que son bien conocidos pero que suelen llevar a confusión, como registro o licencia, y plantearemos otros nuevos, por ejemplo la necesaria distinción entre licencia «gruesa» y «menuda». Por último, aportaremos una serie de ejemplos que demuestran la conveniencia de recurrir al cruzado documental para vincular esta primera etapa del proceso de la trata con aquellos aspectos paralelos o posteriores que los libros no llegan a iluminar.

8 Pérez García, 2015, 832-833.

9 Como señala Eagle (2019, 140), parte de la información incluida en los libros sí resulta más genérica y fragmentaria, por ejemplo, aquella relacionada con la zona de carga o con el destino de las remesas. Otro inconveniente de esta fuente es la ausencia de datos para los años de 1547 a 1560. 


\section{Etapas y perfiles del sistema}

\section{Etapa de concesión de licencias y beneficiarios}

El sistema esclavista castellano del siglo XVI obligaba a presentar una licencia por cada esclavo registrado y pasado a las Indias, norma aplicable tanto a los cargados a modo de mercancía — que son los recogidos en los libros-registro - como a los esclavos domésticos que acompañaban a los pasajeros. Los primeros viajaban con licencia «gruesa» y los de servicio con licencia «menuda» o «de a dos ducados», siempre según la terminología empleada por los oficiales reales. ${ }^{10} \mathrm{El}$ marco cronológico del sistema se sitúa entre 1518, con el inicio del control administrativo del tráfico esclavista por parte de la Casa de la Contratación, y 1595, fecha en la que se firma el primer asiento con el portugués Pero López Reynel. ${ }^{11}$

Las licencias gruesas emanan de una real cédula despachada a petición de parte donde se indican tanto las cantidades otorgadas al beneficiario como las condiciones de la prerrogativa. Esta etapa, que llamamos de concesión, queda reflejada en los libros mediante un traslado de la cédula original: un trámite obligatorio y como tal recogido siempre en la propia escritura. ${ }^{12}$ En determinados momentos del siglo pueden acompañar a la copia otra serie de elementos de carácter informativo, como un encabezamiento con los datos básicos de la merced o notas marginales certificando el pago de los derechos correspondientes. ${ }^{13}$ Las cédulas arrancan con el protocolo «por la presente damos licencia y facultad a vos... o a quien vuestro poder

10 Véanse a este respecto los libros de cargo y data del secretario Ochoa de Luyando. AGI, Contaduría, 36.

11 Se concedieron algunas licencias antes de esa fecha y se dieron pasos importantes hacia la posterior sistematización, por ejemplo, comenzando a cobrar derechos por cada licencia, Vila Vilar, 1983, 114.

12 Real cédula a Pedro de Morga y Jimeno de Bertendona concediéndoles 330 licencias para pasar esclavos a las Indias, Tortosa, 4 de abril de 1564, AGI, Contratación, 5761, 1. 4, f. 103rv, foliación moderna (f. m.). En el documento leemos lo siguiente: «Y mandamos a los dichos nuestros oficiales que residen en la dicha çibdad de Sevilla que tomen en su poder esta mi cédula original y la asienten en los nuestros libros que ellos tienen tocantes a licencias de esclavos, y firmen todos tres sus nombres en el asiento de esta cédula, y ansí mismo firmen en las espaldas de ella».

13 Real cédula a Nicolás de Monardes concediéndole 200 licencias para pasar esclavos a las Indias, Madrid, 28 de junio de 1561, ibidem, f. 32rv, f. m. El encabezamiento previo al traslado reza lo siguiente: «Licencia al doctor Monardes, médico, para que pueda pasar a las Indias, él o quien su poder oviere, dozientos esclavos negros, el terçio hembras, por quanto ha pagado en esta casa dos mil ducados de contado y se a obligado y dado seguridad de pagar otros quatro mil dentro de un año, que es a razón de a treinta ducados cada esclavo». 
hubiere», un formulismo más relevante de lo que parece, ya que abre la puerta a la circulación de las licencias por los mercados hispalenses.

Al estar concebidas como un privilegio, lo normal era conceder las licencias con importantes exenciones. El convento salmantino de San Agustín, por ejemplo, fue devastado por un incendio y obtuvo en compensación licencias libres, «así de los dos ducados de la liçençia de cada uno de ellos, como de los derechos de almoxarifazgo y de otros qualesquier que de ellos se me devan en las dichas Indias». ${ }^{14}$ Este almojarifazgo de Indias, habitualmente redimido, implicaba pagar entre el 5 y el 7,5\% del valor del esclavo ${ }^{15}$ y es distinto del almojarifazgo de Sevilla, que raras veces se perdonaba. El navegante Gregorio de Ugarte, por ejemplo, percibió un lote de 50 licencias gravadas, según figura en la cédula, con «el almoxarifazgo que agora nuebamente se cobra en la çiudad de Sevilla de los esclavos que se lleban a las Indias», ya que, insiste el monarca, «de ello no os hago libre». En este y otros casos se recuerda que los esclavos embarcados en ruta también estaban sujetos al pago de la tasa «como si saliérades con los dichos esclavos de la dicha çiudad de Sevilla». ${ }^{16}$ De cualquier forma, a los beneficiarios del perfil de Ugarte no les afectaban los impuestos aduaneros, ya que nunca eran ellos los cargadores finales de los esclavos. Los mayores alivios para la Real Hacienda llegaban por medio de los grandes lotes de licencias concedidos a los traficantes de más renombre. Rodrigo de Illescas, por ejemplo, tuvo que desembolsar 7.500 ducados para conseguir 250 licencias. En estos casos, el monarca ofrecía facilidades de pago consistentes en abonar una tercera parte al contado y el resto a un año vista, siempre exigiendo fianzas que acreditasen la solvencia económica del beneficiario. ${ }^{17}$

Otro aspecto sensible reflejado en las cédulas es el fraude, por lo visto bastante extendido: «no carguéis en Cabo Verde ni en otra parte más esclabos de los que registráredes, y que si los cargáredes sean perdidos y que se os puedan tomar de los que quedaren bibos». ${ }^{18}$ Así, en 1557, se

14 Real cédula al prior y frailes del convento de San Agustín de Salamanca concediéndoles 67 licencias para pasar esclavos a las Indias, Madrid, 4 de abril de 1590, AGI, Contratación, 5762, 1. 8, ff. 260r-261r, f. m.

15 Lucena Salmoral, 2005, 10.

16 Real cédula al capitán Gregorio de Ugarte concediéndole 50 licencias para pasar esclavos a Nueva España, Madrid, 22 de julio de 1579, AGI, Contratación, 5762, 1. 7, ff. 124r-125r, f. m.

17 Real cédula a Rodrigo de Illescas concediéndole 250 licencias para pasar esclavos a las Indias, pagando 2.500 ducados al contado y los 5.000 restantes en un plazo no superior a un año, Valladolid, 9 de mayo de 1565, AGI, Contratación, 5761, 1. 4, f. 147rv, f. m.

18 Real cédula a Juan de Loviano concediéndole 50 licencias para pasar esclavos a las Indias, El Bosque de Segovia, 20 de mayo de 1566, ibidem, ff. 200r-201r, f. m. 
determinó que «el barquero que echare en tierra negro o negra sin licencia de los susodichos, por el mismo caso pierda la barca y sea preso por término de treinta días». ${ }^{19}$

Los comerciantes portugueses tampoco lo tuvieron sencillo en un principio, ya que se les tildaba de «marranos» o falsos conversos ${ }^{20}$ En una adjudicación de licencias dada en 1543 al financiero Domingo de Lizarraras, por ejemplo, se permitía que los esclavos navegaran en barcos portugueses o con tripulación portuguesa, pero ninguno podía «saltar en tierra» al llegar a las Indias, a excepción del maestre, el escribano y el despensero del navío. ${ }^{21}$

Si los esclavos fallecían durante el viaje o no los había en número suficiente al llegar a las zonas de rescate, el monarca podía conceder nuevas licencias, siempre y cuando el cargador cumpliera con sus obligaciones fiscales: «y con que si después de enbarcados los dichos esclavos se os muriere alguno de ellos en la mar, no seamos obligados a daros nueva licencia para que carguéis otros en su lugar si no fuere pagando de nuevo los derechos de ellos». ${ }^{22}$ Algunos traficantes no estaban por la labor de volver a pagar y terminaban envueltos en largos y costosos pleitos judiciales. Así le sucedió a Pedro Mollinedo tras registrar una remesa de 100 esclavos de los que solo 65 llegaron a Indias. ${ }^{23}$ Más facilidades encontró Lizarraras, quizás privilegiado por su condición de banquero y prestamista del emperador, ${ }^{24}$ toda vez que, para completar un registro fallido «hasta que verdaderamente se cunpla el número», solo tuvo que presentar un escrito rubricado por el escribano del navío donde figurase la causa de la muerte de los esclavos. ${ }^{25}$ A finales de siglo, ya en época de asientos, se concedía un descuento del $10 \%$ sobre el precio de las licencias en previsión de posibles pérdidas, cifra que Henri Lapeyre considera insuficiente a tenor de las pésimas condiciones sanitarias de las naves. ${ }^{26}$

19 «Que no se desembarquen negros en las Indias sin licencia de la justicia y oficiales reales», Recopilación de leyes de los Reynos de las Indias..., 1841 [1681], t. III, 1. VIII, tít. XVIII, ley II.

20 Mateus Ventura, 1999, 36.

21 Real cédula a Domingo de Lizarraras concediéndole 50 licencias para pasar esclavos a las Indias, Valladolid, 21 de septiembre de 1543, AGI, Indiferente, 423, 1. 20, ff. 685v-686v, f. m.

22 Real cédula a Pedro de Morga y Jimeno de Bertendona concediéndoles 330 licencias para pasar esclavos a las Indias, Tortosa, 4 de abril de 1564, AGI, Contratación, 5761, 1. 4, f. 103rv

23 Ejecutoria del pleito litigado entre Pedro de Mollinedo y el fiscal del Consejo de Indias sobre nuevas concesiones de licencias, Toledo, 9 de noviembre de 1561, ibidem, ff. 1r-4r.

24 Carande, 1983 [1967], I:199.

25 Real cédula a Domingo de Lizarraras concediéndole 50 licencias para pasar esclavos a las Indias, Valladolid, 21 de septiembre de 1543, AGI, Indiferente, 423, 1. 20, ff. 685v-686v, f. m.

26 Lapeyre, 1967, 303. 
Las cédulas contienen otro tipo de cláusulas que podemos considerar variables según el destinatario o las circunstancias de cada época. En los años treinta hacen referencia a la prohibición de llevar individuos de la etnia wólof por ser responsables, al parecer, de ciertos alzamientos y muertes de cristianos en la isla de San Juan. ${ }^{27}$ Una cédula de 1534, por ejemplo, condicionaba la validez de las licencias a que los esclavos pasados no fueran «de los de Gilofe $[s i c]$ ni de los otros prohibidos». ${ }^{28}$ Otra fuente de controversia fue el establecimiento de un precio tope en las Indias. Entre 1541 y 1561, hubo diferentes disposiciones al respecto según la zona de venta y la procedencia del esclavo, en general con malos resultados. Al parecer, hubo un aumento considerable del fraude,$^{29}$ un estancamiento del tráfico esclavista («no se llevan a las dichas nuestras Indias tantos esclavos como son neçesarios para hechar en las minas y entender en la labrança de la tierra») y un aumento de la presión sobre el indio. Tal fue así que, en septiembre de 1561, la Corona renunció a intervenir en este aspecto («que cada uno pueda vender los dichos negros a los más justos preçios que pudiere"), ${ }^{30}$ quizás también como compensación a un incremento brusco y repentino de la carga fiscal sobre la licencia. De este modo, vemos cómo las futuras concesiones se hacen eco de esta situación. Al mercader Jácome de Mallea, por ejemplo, se le recuerda que puede vender sus esclavos en Indias «al preçio o preçios justos que quisiéredes e por bien tuviéredes, por quanto la tasa que por nos estava puesta çerca del valor a que se avían de vender los negros en las Indias, está por nos rebocada». ${ }^{31}$ En algunos lugares, como Cuba, se mantuvo una cierta limitación, ya que estaba prohibido vender un esclavo por un precio mayor del que se le hubiera adjudicado al momento de llegar a la isla. En opinión de Ramiro Guerra esto perjudicaba al comprador de bozales, ya que, tras invertir tiempo en su formación, luego no podía pedir más dinero por ellos. ${ }^{32}$

Al finalizar el traslado de la cédula y siempre antes de la cuenta de registro, los oficiales podían incluir otros datos directamente relacionados con la concesión; desde copias adicionales de documentos hasta información

27 Lucena Salmoral, 2005, 45.

28 Real cédula a Juan de Turégano concediéndole 10 licencias para pasar esclavos a las Indias, Palencia, 6 de agosto de 1534, AGI, Contratación, 5760, 1. 2, f. 22 r.

29 Díaz Soler, 1970 [1953], 66.

30 Real cédula revocando el precio tope de venta de los esclavos que llegaban a las Indias, Madrid, 15 de septiembre de 1561, AGI, Indiferente, 427, 1. 30, ff. 122v-123v.

31 Real cédula a Jácome de Mallea concediéndole 70 licencias para pasar esclavos a las Indias, Madrid, 19 de diciembre de 1568, AGI, Contratación, 5761, 1. 5, ff. 16r-17r.

32 Cit. en Arriaga Mesa, 1999, 18-20 
contable, siempre presente en las permutas de licencias por deudas de juros que tan habituales fueron a partir de la década de $1560 .{ }^{33}$ Luis Colón, por ejemplo, se acogió a esta medida con mucha frecuencia, convirtiéndose de esta forma en uno de los mayores beneficiarios de licencias del siglo. En este sentido, es importante matizar que estas personas no son traficantes o «compradores de esclavos», ${ }^{34}$ sino que responden al perfil de un gran acreedor, de un beneficiario que no busca efectuar registros ni tiene interés alguno en la trata, sino que encuentra en las concesiones un recurso puntual, en este caso frente a una serie de deudas incobrables.

La mención a Luis Colón nos sirve para entrar de lleno en la cuestión de los perfiles y su proyección al caso vasco. Antes de 1540, las concesiones fueron pocas y dirigidas a entornos concretos y privilegiados. Este período estuvo condicionado por los asientos de carácter monopolístico que los compromisos de Carlos V le obligaron a adquirir con el entorno de los Welser y con otros individuos de su círculo cercano, como Laurent de Gouvenot. ${ }^{35}$ Esta política tuvo, a la sazón, dos grandes grupos de perjudicados: los mercaderes de Sevilla, que vieron estancada la circulación de licencias, y los residentes en La Española, donde no llegaban suficientes esclavos y los pocos se vendían a precios desorbitados: «con el estanco de negros por lo capitulado con los alemanes no podemos haber uno por el ojo de la cara». ${ }^{36}$ A los vascos también les afectó este problema, ya que en un principio las licencias se repartieron entre una minoría de grandes comerciantes con vínculos en las altas instituciones, o entre cortesanos como Diego de Zárate y Alonso de Idiáquez, personas de la total confianza del emperador. ${ }^{37}$ Al producirse el desbloqueo definitivo de las adjudicaciones, la cantidad de beneficiarios se disparó. Llegado el ecuador del siglo, los mayores favorecidos fueron algunos financieros, como Domingo de Lizarraras y los hermanos Arbieto, además de grandes cargadores como Pedro de Mollinedo,

33 Real cédula a Juan López de Zubizarreta concediéndole 135 licencias para pasar esclavos a Indias, El Pardo, 6 de julio de 1574, AGI, Contratación, 5761, 1. 6, ff. 9r-10v, f. m.

34 Lorenzo Sanz, 1979, II:541.

35 Enrique Ehinger y Jerónimo Sailer, beneficiarios de 4.000 licencias monopolísticas, eran los factores de los Welser en Castilla. Esta potente casa financiera, radicada en Aubsburgo, había comenzado a tomar posiciones en las Indias, consiguiendo en arriendo el territorio de Venezuela y desplazando factores comerciales autorizados, como Lázaro Nurenberg o Jácome Cronberger. Ramos Pérez, 1976, 23.

36 Saco, 1879, I:146.

37 Los Urrutia mantuvieron estrechos vínculos con los Matienzo (Otte, 1964, 5), cuyo miembro más conocido, Sancho, fue tesorero de la Contratación. Zárate, por su parte, estuvo en la primera coronación imperial en Aquisgrán y fue también oficial de la misma institución. Díaz de Durana y Otazu, 2008, 153. 
antiguo criado y sucesor de los Urrutia. Los años sesenta marcaron el pico máximo de las concesiones, en su mayoría acaparadas por el entorno de Pedro de Morga y por algunos comerciantes curtidos en la gran plaza financiera de Burgos, como Andrés de Larrea.

El rastreo de la presencia vasca en los otorgamientos recogidos en los libros-registro de esclavos y en otras fuentes complementarias ${ }^{38}$ nos ofrece un resultado de 69 cédulas despachadas en favor de individuos de esta procedencia, todas las cuales totalizaron 7.617 licencias. Para buena parte de ellas (4.937), contamos con datos de registro asociados, ${ }^{39}$ una muestra considerable y creemos que suficiente para efectuar una primera aproximación a las dinámicas seguidas por estas personas.

\section{TABla 1}

\section{LICENCIAS CONCEDIDAS A BENEFICIARIOS DE ORIGEN VASCO} (SOLO CÉDULAS CON DATOS DE REGISTRO)

\begin{tabular}{|c|c|c|c|}
\hline \multirow[b]{3}{*}{ Concesiones } & \multicolumn{3}{|c|}{ Destino de las licencias } \\
\hline & \multicolumn{2}{|c|}{ Mercado secundario } & Cargazones \\
\hline & Cedidas & Traspasadas & Registradas \\
\hline 4.937 & 901 & 3.459 & 577 \\
\hline $100 \%$ & $18,24 \%$ & $70,06 \%$ & $11,70 \%$ \\
\hline
\end{tabular}

Fuente: AGI, Contratación, 5760, 5761 y 5762. Elaboración propia.

El beneficiario de licencias disponía de tres opciones: emplearlas para registrar esclavos, traspasarlas o cederlas. En el caso vasco, y muy probablemente a nivel general, la tendencia mayoritaria fue el traspaso, lo que en la práctica significaba desapoderarse por completo de los títulos. Si la licencia, como ya hemos indicado, era una merced y los beneficiarios, no pocas veces, individuos ajenos a la trata, resulta coherente que su principal intención fuera obtener un rendimiento económico inmediato. Su función, de cualquier manera, era importante, ya que con esa primera venta se daba inicio al mercado secundario y al proceso de distribución de las licencias. En nuestro ámbito de estudio, estos títulos financiaron las empresas

38 AGI, Indiferente, 420, 421, 424, 425. AGI, Contaduría, 36.

39 El resto corresponden al período para el cual carecemos de datos de registro (1547-1561). 
conquistadoras de Juan Ortiz de Zárate o Pascual de Andagoya; cancelaron la gran deuda contraída con el alto cargo indiano Diego de Ibarra; premiaron los servicios de guerra y marinería de navegantes como Gregorio de Ugarte, Matías de Landecho o Jerónimo de Zurbano, y reconocieron también la fidelidad de ministros y favoritos del monarca como Juan López de Zubizarreta o el mencionado Diego de Zárate. ${ }^{40}$ La cesión, por su parte, era una especie de endoso con limitaciones y solo facultaba a quien la recibía para realizar un registro. Requería un conocimiento avanzado del mundo comercial y disponer de una amplia cartera de contactos, razón quizás de que no fuera la opción prioritaria de estos individuos. Los registros directos también son escasos y se corresponden en su mayoría con las licencias adjudicadas al gran traficante Pedro de Morga. Hay más comerciantes de renombre en la nómina de beneficiarios pero provienen, como ya hemos señalado, del espacio económico burgalés y parecen especializarse en el negocio de la distribución, caso de la familia Arbieto o Andrés de Larrea. ${ }^{41}$

\section{Mercado secundario: compradores y/o distribuidores de licencias}

En la etapa de concesión, muchas de las licencias quedaban inmovilizadas en tanto el - en ocasiones - inexperto beneficiario no llegase a un acuerdo para traspasar o ceder al menos una parte a un especulador o cargador de esclavos; un proceso que podía ser muy rápido en épocas de alta demanda o demorarse durante años. Si la opción elegida era el traspaso, los oficiales dejaban constancia de ello antes o durante la cuenta de registros, proporcionando algunos datos básicos sobre la transacción: intervinientes, cantidad de licencias traspasadas, fecha, escribano que refrendó la escritura, etcétera. ${ }^{42}$ Este mercado secundario podía adquirir tal complejidad que su seguimiento resultaba trabajoso incluso para los secretarios encargados

40 Estos perfiles coinciden en líneas generales con los observados en otros estudios. García Fuentes, 1982, 9. cuadro 1

41 Para consultar los datos desglosados de cada beneficiario, véase Ortiz Arza, 2019, II,

42 Real cédula a Juan López de Zubizarreta concediéndole 135 licencias para pasar esclavos a las Indias, El Pardo, 6 de julio de 1574, AGI, Contratación, 5761, 1. 6, ff. 9r-10r, f. m. El aviso de traspaso que sigue al traslado de la cédula, dice así: «Tiene poder del dicho Juan López de Subiçarreta para pasar y cargar los çiento y treinta y cinco pieças de esclavos negros en la dicha çédula real contenidos a las Indias, Juanes de Ismendi, vezino de esta ciudad de Sevilla, que paresçe que pasó ante Juan de Mitarte, escribano de Su Magestad en la villa de Madrid, a diez y seis días del mes de julio de mil y quinientos y setenta y quatro años». 
de llevar el control: «Doze licençias que se libraron por el dicho alcalde al dotor Simón de Tovar, y el susodicho las çedio en Çesar Baronçini, y el susodicho las bolvió a çeder en Melchor Pérez de Çerbantes ante Joan Baptista Ortiz, escrivano en quinze de henero de este año de ochenta y seis, el qual las çedió al dicho Miguel Martínez». ${ }^{43}$

Según Rolando Mellafe, una licencia por la que el beneficiario inicial hubiera pagado 30 ducados en tasas, podía venderse hasta por 80 ducados al final del proceso. ${ }^{44}$ Nuestra impresión es que se trataba de un mercado muy fluctuante que, por lo general, se movía lejos de esas cifras. Recordemos que algunas personas recibían las licencias con importantes exenciones fiscales o sin gravámenes de ningún tipo, siendo posible, en tales casos, obtener beneficio incluso vendiendo a bajos precios. Otras veces no les quedaba más remedio que malvender; Juan de Corrales, por ejemplo, se lamentaba de haber traspasado un lote de licencias a Juan de Echagoya por tan solo 15 ducados la unidad, todo ello tras no haber «hallado quien más preçio por ellas me diese».$^{45}$ Los propietarios confiaban la tarea a los corredores de lonja, que se encargaban de pregonar las licencias disponibles y en ocasiones terminaban participando directamente en un negocio que conocían de primera mano. ${ }^{46}$

Existieron otras situaciones por las que un lote de licencias podía circular o cambiar de manos. Cuando no había un beneficiario físico, como sucedió con las 500 licencias otorgadas a la isla de Cuba, se encomendaba el reparto a la Casa de la Contratación, que las vendía «juntas o por menudo» y nunca por menos del valor en que «se venden las otras liçençias que se dan para las Indias libres de derechos». ${ }^{47}$ También podían quedar licencias vacantes si el adjudicatario no las aceptaba. El oficial Juan Palacios, por ejemplo, tuvo que desplazarse hasta Marchena para notificar a Diego Manuel Bocarro que su solicitud de 400 licencias había sido aceptada, pero este dijo encontrarse enfermo de peste y no saber «cosa alguna de ello». Llegados a este punto, las licencias quedaban de nuevo en manos de los

43 Asiento sobre la circulación de doce licencias procedentes de la liquidación de bienes de Pedro de Morga, Sevilla, ca. 1586, AGI, Contratación, 5761, 1. 6, f. 32r, f. m.

44 Mellafe, 1973, 45.

45 Juan de Corrales vende a Juan de Echagoya 50 licencias para pasar esclavos a las Indias, Sevilla, 5 de diciembre de 1588, Archivo Histórico Provincial de Sevilla (AHPSe), Protocolos Notariales de Sevilla, 14357, ff. 282r-284r.

46 Pedro de Morga fue corredor de lonja en sus inicios. Angulo, 2012, 243.

47 Asiento sobre la forma en que se han de vender las 500 licencias concedidas a la isla de Cuba, ca. 1551, AGI, Contaduría, 36, n. 5, f. 971r. 
jueces y la Audiencia de la Contratación, que en esta ocasión decidieron venderlas directamente a otras personas, ya fueran «juntas o divididas», y siempre en la forma «en que mexor se pudieren despachar». Al igual que sucedía con las ventas entre particulares, primero se informaba de la disponibilidad de las licencias, tanto en las gradas de mercaderes como en el patio de la Contratación, tarea que en este caso llevó a cabo el pregonero Francisco de Villanueva, «a altas bozes y en faz de mucha gente». No hubo rebajas y el precio fijado fue de 30 ducados por licencia, el mismo que hubiera tenido que pagar Bocarro. ${ }^{48}$

Otra circunstancia por la que un lote podía quedar liberado era la quiebra de un banco público. A Pedro de Morga le sorprendió la bancarrota de 1576 mientras preparaba una importante remesa de esclavos junto a Diego Felipe de Andino. Las licencias, como parte de los activos del magnate vizcaíno, fueron adjudicadas a sus acreedores para su posterior liquidación. ${ }^{49}$

Una de las facetas más importantes del mercado secundario es sin duda su vinculación con el mundo de las finanzas; no solo con los banqueros de Sevilla como Morga o Matías de Fano - su socio al momento de la quiebra-, sino también con las grandes casas castellanas y europeas, como los Ruiz, Affaitati o Welser. ${ }^{50}$ Unos y otros advierten pronto el potencial de la licencia como activo económico de gran demanda y alta liquidez, todo ello al mismo tiempo que surge la figura del comprador de licencias: un inversor interesado en controlar la distribución a base de acaparar los grandes lotes en un proceso que albergaba un alto componente especulativo y tendía a fragmentar los registros.

Al estudiar el mercado secundario a través de los libros-registro de esclavos, tropezamos con frecuentes errores y omisiones de información que impiden seguir el rastro de muchas licencias. ${ }^{51}$ Por este motivo, hemos trabajado únicamente con lotes completos cuya procedencia y destino final conocemos con seguridad. La muestra recogida en la Tabla 2 no representa la totalidad de las licencias compradas por los comerciantes vascos, pero es suficiente para señalar una serie de tendencias.

48 Real cédula a Diego Manuel Bocarro concediéndole 400 licencias para pasar esclavos a las Indias, Madrid, 20 de diciembre de 1568, AGI, Contratación, 5761, 1. 5, ff. 82r-87r, f. m.

49 Asiento sobre el reparto de licencias entre los acreedores de Pedro de Morga, AGI, Contratación, 5761, 1. 6, f. 29v, f. m.

50 Los ya mencionados Ehinger y Sailer, beneficiarios de 4.000 licencias, representaban a la casa alemana. Por otro lado, varias de las licencias adjudicadas a Luis Colón fueron vendidas a los Affaitati de Cremona por 3.300 ducados. Fernández Martín, 1986, 61.

51 Lo más frecuente es encontrar registros sin información sobre el propietario de la licencia. 
TABLA 2

LICENCIAS COMPRADAS POR PERSONAJES DE ORIGEN VASCO

\begin{tabular}{|c|c|c|c|}
\hline \multirow[b]{3}{*}{ Compras } & \multicolumn{3}{|c|}{ Destino de las licencias } \\
\hline & \multicolumn{2}{|c|}{ Mercado secundario } & Cargazones \\
\hline & Cedidas & Traspasadas & Registradas \\
\hline 1.760 & 1.030 & 80 & 650 \\
\hline $100 \%$ & $58,52 \%$ & $4,55 \%$ & $36,93 \%$ \\
\hline
\end{tabular}

Fuente: AGI, Contratación, 5760, 5761 y 5762. Elaboración propia.

Si los beneficiarios prefieren traspasar sus licencias, los compradores optan por cederlas, lo que sucede en el 58,52 \% de los casos estudiados. La diferencia principal radica en las alternativas que una y otra opción proporcionan: mientras el traspaso otorga pleno dominio sobre la licencia, siendo posible canjearla por registros, cederla, revenderla, utilizarla como método de pago y fianza, etcétera, la cesión solo faculta a quien la recibe para efectuar registros. Todo ello guarda relación con un cambio en el perfil de las personas que se aproximan a este mercado, que será muy distinto al de los beneficiarios. Si estos eran conquistadores, acreedores, cortesanos y otros favoritos del monarca, siempre ansiosos por desprenderse de las licencias, los nuevos propietarios son comerciantes de corte financiero mucho más interesados en explorar todo el abanico de opciones que estos activos pueden ofrecer. Son personas, ahora sí, expertas en los negocios y muy cercanas a los traficantes, con los que construyen una relación de dependencia. Algunos de los compradores son de hecho los propios cargadores, generalmente los más poderosos y acaudalados, que ya aparecían en la fase anterior, pero que ahora adquieren un protagonismo mucho mayor. Tal es así que el porcentaje de registros directos se incrementa hasta el 36,93\%, aunque también reservan parte de sus licencias para ofrecer cesiones, una forma rápida de rentabilizar su inversión sin necesidad de correr riesgos. La opción de volver a traspasar las licencias existe pero es marginal, quizás porque encarece progresivamente el producto, reduciendo al mismo tiempo su rentabilidad. En este sentido, es posible que hubiera diferencias de precio entre un traspaso y una cesión, o entre una licencia exenta y otra lastrada por gravámenes. 
Los vascos que participan en esta fase de la trata son siempre fortunas mercantiles con capacidad para acceder a los grandes paquetes de licencias: ${ }^{52}$ cargadores de esclavos, como Juan de Narria, Pedro de Murueta o Juan de Urrutia; banqueros públicos de Sevilla como Sancho de Monasterio, Domingo de Lizarraras o Pedro de Morga, y miembros de linajes comerciales vinculados al mercado de las rentas, como Lucas de Iturbe, un especialista que fue el encargado de distribuir por los mercados hispalenses la gran concesión de 916 licencias recibida por Diego de Ibarra. ${ }^{53}$ La sombra del poderoso Simón Ruiz también aparece en el mercado secundario, en este caso a través del vasco Pedro de Tolosa, uno de sus factores en Sevilla, al que vemos adquiriendo un paquete de 41 licencias que cedió, muy fragmentado, a un amplio grupo de pequeños cargadores. ${ }^{54}$

\section{Etapa de registro y «rasgado» de la licencia: cargadores de esclavos}

La cuenta de registros asociada a cada cédula es el principal trámite recogido en los libros de Contratación. Su objetivo es comprobar que se cumple el principio de un esclavo registrado por cada licencia concedida, siempre con el fin de evitar fraudes como la reutilización. ${ }^{55}$ La práctica administrativa a la hora de presentar los datos no cambia demasiado con el paso del tiempo y los registros se anotan de forma seriada y cronológica hasta consumir la cantidad de licencias estipulada en cada prerrogativa. Parte de la información es constante y apta para su procesamiento, como es la fecha y el número de esclavos registrados, el cargador que envía la remesa, el maestre - en ocasiones se confunde con el armador- del barco que la transporta y finalmente, aunque con reservas, el propietario de la licencia que faculta el registro.

52 Para los datos desglosados de los compradores de licencias, véase Ortiz Arza, 2019, II,

53 Real cédula a Diego de Ibarra concediéndole 916 licencias para pasar esclavos a las Indias, AGI, Contratación, 5762, 1. 8, ff. 1r-2r, f. m. En la cuenta de registros (ff. 3r-13r) se puede comprobar cómo Iturbe cedió varias de las licencias a cargadores vascos.

54 Asiento sobre el traspaso de 41 licencias de Bernaldino Súarez de Mendoza a Pedro de Tolosa, Sevilla, 1591, AGI, Contratación, 5762, 1. 8, f. 309v, f. m. Sobre las relaciones entre los Tolosa y los Ruiz, véase Crailsheim, 2016, 248.

55 Mira Caballos, 1994, 280. 
FIGURA 1

REGISTRO DE DIEZ ESCLAVOS, «EL TERÇIO DE HENBRAS», EFECTUADO POR AMBROSIO DE UNDA EN LA NAO DEL MAESTRE FRANCISCO RAMÍREZ

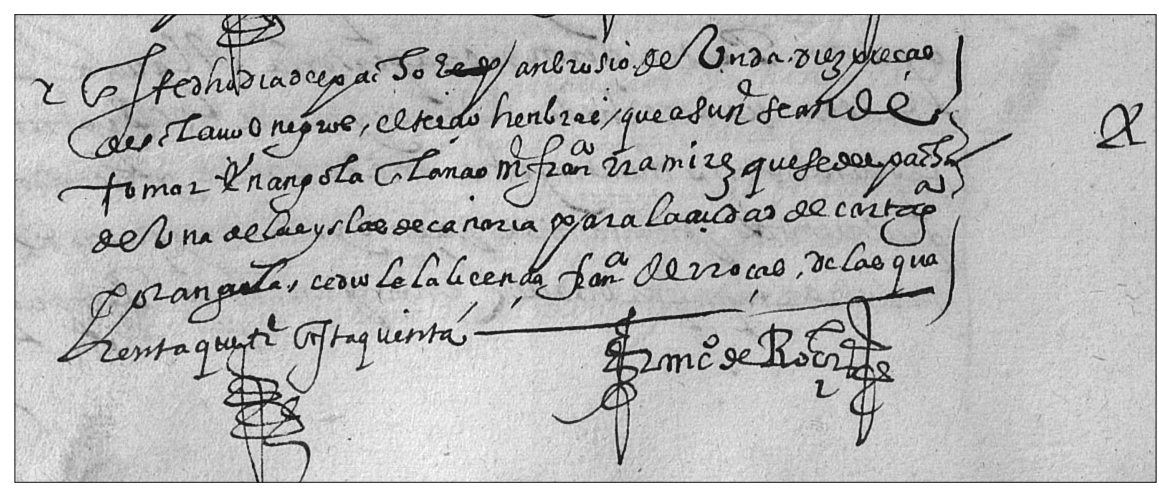

La nave, con destino a Cartagena de Indias, hizo escala en Angola para cargar los esclavos. Cedió la licencia Francisco de Rozas que, según se indica, contaba con un lote de cuarenta y cuatro unidades.

Fuente: AGI, Contratación, 5762, lib. 8, f. 210, f. m.

A este último lo identificamos gracias a la firma que suele aparecer en la parte inferior del asiento; puede ser la misma persona que envía los esclavos u otra diferente, en cuyo caso hablaríamos de una cesión de licencias tal y como sucede en la imagen sobre estas líneas. En un principio, este dato se omite o se resuelve con una simple mención del oficial a cargo, pero pronto será habitual que el titular firme el registro y aporte documentación que acredite su dominio sobre la licencia, quedando este hecho anotado en el reverso de la escritura. ${ }^{56}$

Otra información frecuente es la que alude al lugar de embarque de los esclavos, que puede aparecer indicado en el propio asiento (Figura 1) o mediante nota al margen, pero solo cuando se produce fuera de Sevilla, ya sea en Cádiz, Canarias, Cabo Verde, Guinea, Angola o Santo Tomé. ¿Significa esto que el resto de embarques, donde no hay mención alguna al respecto, se efectúan en la capital hispalense? Por el momento no lo podemos asegurar, pero si el cotejo documental confirmase este extremo en

56 Pérez García, 2015, 833. 
una mayoría suficiente de casos, estaríamos ante otro dato de mucho interés para el investigador. ${ }^{57}$

Algo vagas son también las menciones al sexo de los esclavos. En ocasiones este dato se indica con claridad: «en X de febrero de IUDLXVII años, sacó Ximeno de Vertendona un esclavo y una esclava negra en la nao maestre Pedro de la Torre». ${ }^{58}$ Otras veces, sin embargo, no hay distinción alguna y tan solo figura la fórmula «esclavos negros», pero no podemos afirmar que estos casos apunten a un registro netamente masculino. No será hasta finales de siglo cuando se preste más interés en precisar esta información: «despachó Diego López de Oria dos esclavas negras henbras en la nao maestre Pedro de Araneder, a Tierra Firme». O bien, «despachó Vicente Orsuche dos esclavos negros barones, a Diego de Torrijos, a Cartagena». ${ }^{59}$ Los registros proyectados para cargar en África no aclaran nada a este respecto, como es lógico, pero sí recuerdan que una tercera parte de los cautivos — de manera aproximada- deben ser mujeres. ${ }^{60}$ No era este un asunto baladí, como bien pudo comprobar Rodrigo Bazo, al que le fueron requisados 10 esclavos de los 162 que envió a Tierra Firme por contener dicha remesa un exceso de varones. ${ }^{61}$

Por otro lado, era frecuente que muchas esclavas viajasen con sus hijos de corta edad. Esta circunstancia se suele indicar, pero sin incluir a la criatura en la cuenta de registros: «en este dicho día sacó y registró Juan de Bustinça un esclavo y una esclava negra, y la esclava con una cría a los pechos, en la nao maestre Esteban de Çubieta». ${ }^{62}$ Hay otros casos, como un registro de «dos esclavos negros, uno de ellos muchacho», efectuado por

57 Eagle y Wheat $(2020,56)$ aportan un ilustrativo esquema sobre las zonas de carga y el destino de 804 esclavos pasados con licencias de Rodrigo Bazo.

58 Registro de dos esclavos efectuado por Jimeno de Bertendona, Sevilla, 10 de febrero de 1567, AGI, Contratación, 5761, 1. 4, f. 206v, f. m.

59 Registro de dos esclavas efectuado por Diego López de Oria, Sevilla, 23 de enero de 1596, AGI, Contratación, 5762, 1. 8, f. 354v, f. m. Registro de dos esclavos realizado por Vicente Orsuche, 24 de enero de 1596, idem.

60 Registro de ocho esclavos efectuado por Martín López de Isasi, AGI, Contratación, 5762, 1. 9, f. 149v, f. m. El asiento completo dice así: «En XXIX de diziembre de IUDLXXXV años, despachó Martín López de Isasi ocho pieças de esclavos negros, el terçio henbras, que a su nonbre se an de tomar en Cavo Verde en la nao maestre Pedro de Morueta».

61 Real cédula a los oficiales de Castilla del Oro ordenando que se restituyan a Rodrigo Bazo los 10 esclavos que le habían tomado o su precio equivalente, Valladolid, 29 de diciembre de 1557, AGI, Panamá, 236, 1. 9, ff. 249v-250v.

62 Registro de dos esclavos efectuado por Juan de Bustinza, Sevilla, 31 de mayo de 1582, AGI, Contratación, 5762, 1. 7, f. 73r, f. m. 
Domingo de Corcuera, pero en general es muy poco lo que la fuente aclara sobre la edad y características de los esclavos pasados. ${ }^{63}$

También es habitual encontrar anotaciones marginales que corrigen errores o señalan cambios en los registros, indicando casi siempre las nuevas fechas y condiciones. ${ }^{64}$ De especial interés resultan aquellas que entran en detalles sobre las incidencias o imprevistos acaecidos a la hora de enviar una remesa concreta. Recogemos a continuación algunos motivos por los que un registro podía llegar a modificarse:

- Naufragio o daño del barco antes de salir a mar abierto. En mayo de 1584, por ejemplo, Juan de Goyaz perdió una esclava al naufragar la nao de Rodrigo Rizo en la barra de Sanlúcar, aunque, según se indica, pudo registrar otra al año siguiente. ${ }^{65} \mathrm{La}$ fuente también menciona un gran incendio que destruyó la flota de Indias de 1596, sin duda como resultado del ataque inglés a Cádiz. En esta ocasión, también fue necesario reubicar a los esclavos y corregir de forma rudimentaria todos los registros previamente asentados. ${ }^{66}$ Por último, gracias a otra nota sabemos que la nao del vasco Martín de Labayen «se perdió en el puerto de la isla de Cabo Verde», donde había llegado para cargar esclavos. ${ }^{67}$

- Indisposición o muerte de un esclavo antes de embarcar. Es lo que le sucedió, por ejemplo, a Domingo de Corcuera, que perdió por enfermedad a una de las seis esclavas que estaba a punto de enviar a las Indias y, si bien consiguió sacar otra en su lugar, tuvo que esperar nada menos que cuatro años. ${ }^{68}$

- Huida del esclavo. Llama la atención el caso de Gonzalo Vázquez, cuya esclava se dio a la fuga antes de la partida del barco y, tras recibir autorización para registrar otra en su lugar, también se le marchó, en este caso, según se indica en la nota, a los «corrales de Chipiona». ${ }^{69}$

63 Registro de dos esclavos efectuado por Domingo de Corcuera, Sevilla, 23 de mayo de 1583, AGI, Contratación, 5762, 1. 8, f. 224v, f. m.

64 El error más frecuente es anotar un registro asociado a una concesión de licencias que no le corresponde, en cuyo caso se tacha el asiento y se realizan las aclaraciones pertinentes. Junto a un registro de Juan Pérez de Córdoba, por ejemplo, podemos leer: «es de las liçençias del mesmo Juan Pérez de Córdoba y se puso aquí por yerro», indicándose a continuación el folio correcto. Nota al margen, Sevilla, ca. 1562, AGI, Contratación, 5761, 1. 4, f. 33v.

65 Nota al margen, Sevilla, 1585, AGI, Contratación, 5762, 1. 7, f. 241r, f. m.

66 Nota al margen, Sevilla, 1597, AGI, Contratación, 5762, 1. 8, f. 348r, f. m.

67 Nota al margen, Sevilla, 1590, ibidem, f. 170v, f. m.

68 Nota al margen, Sevilla, 1589, AGI, Contratación, 5762, 1. 9, f. 121r, f. m.

69 Nota al margen, Sevilla, 1585, AGI, Contratación, 5762, 1. 7, f. 267r, f. m. 
En otro momento vemos tachados dos registros de esclavos asociados a un navío de Ortuño de Trabudo, «porque dixo el dueño que se le huyeron». ${ }^{70}$ Otros decidían lanzarse al agua, como bien pudo comprobar el maestre Miguel de Gordiola cuando tres esclavos «se saltaron» de su barco aprovechando un inminente naufragio. ${ }^{71}$

- Escasez de esclavos. Quizás sea la razón más frecuente por la que un registro se modificaba. Y es que las circunstancias de los remotos parajes africanos escapaban muchas veces al control de los cargadores, a los que nadie aseguraba que los esclavos registrados en Sevilla fueran a estar disponibles a la llegada del navío. Sirva el ejemplo de Martín López de Isasi y Lope de Tapia, que registraron 80 esclavos pero sus factores en Cabo Verde no pudieron embarcar más de $61 .^{72}$

- Prohibición de navegar a las zonas de rescate. Aunque no era la situación más habitual, sabemos que en 1536 se eliminó una partida de 100 esclavos registrados por Juan Núñez por temor a que «murieren de pestilençias en Cabo Verde» y se recomendó que «no fuese esta nao por allí». ${ }^{73}$

- Prohibición contra una persona concreta, como le sucedió a Sebastián Cruzate, en su caso por deseo, desconocemos las razones, del jesuita Diego de Luna: «Ojo [sic], que Sebastián Cruzate no ha de despachar ningún esclavo, como se mandó ante Francisco de Chaves (escribano público) a pedimiento del padre Diego de Luna». ${ }^{74}$

La información sobre factores y consignaciones es escasa, siendo necesario recurrir, la mayoría de veces, a documentación complementaria. Algunos registros incluyen este dato, pero no son mayoría y suelen estar vinculados a ciertos embarques efectuados fuera de Sevilla o a personajes concretos como el portugués Simón de Tovar o Diego y Clemente de Aguinaga, vascos avecindados en Cádiz cuyos registros resultan siempre minuciosos e incluso redundantes en detalles. Por lo general, si aparece el dato de la consignación o el lugar de embarque, suele hacerlo también el de destino: «En XII de julio de IUDXC años despachó Clemente de Aguinaga, por doña Isavel de Ochandiano, un esclavo negro barón en la nao maestre Domingo Sauli, que se despacha en Cádiz para Nueva España consignada

70 Nota al margen, Sevilla, ca. 1530, AGI, Contratación, 5760, 1. 1, sin foliar (s. f.).

71 Nota al margen, Sevilla, ca. 1581, AGI, Contratación, 5762, 1. 7, f. 100r, f. m.

72 Nota al margen, Sevilla, 1586, ibidem, f. 285 rv.

73 Nota al margen, Sevilla, 1536, AGI, Contratación, 5760, 1. 2, f. 44v.

74 Nota al margen, Sevilla, ca. 1590, AGI, Contratación, 5762, 1. 8, f. 183v, f. m. 
[sic] al dicho Clemente de Aguinaga, y por su ausencia a Melchor de Cuéllar, por quenta de doña Isavel de Ochandiano». ${ }^{75}$

En otras ocasiones - muy pocas- se indica que los implicados en el registro llevan compañía comercial para el trato esclavista, como es el caso de dos esclavas registradas «a riesgo de la compañía que el dicho Antonio de Oquendo tiene con el dicho Gonzalo Rodríguez», ${ }^{76}$ o se precisan las obligaciones del consignatario, como sucedió con Juan de Avendaño, a quien Juan Martínez de Arrazola remitió un esclavo «para que lo venda y el proçedido lo envíe registrado en el registro del rey consinado al dicho».77

En vista de la arbitrariedad con la que se recogen algunos datos, es posible que el hecho de añadir más o menos información corresponda en último término a una decisión personal de cada cargador o maestre. Igualmente irregulares son los detalles sobre los navíos o sus características, que también parecen guardar relación con individuos concretos, como el maestre Juan de Zurbano, en cuyos registros se señala tanto el tipo de embarcación — una fragata - como su nombre, Santa Catalina. ${ }^{78}$ A veces se indica que los esclavos viajan en navíos de aviso empleados para transportar cartas, pliegos o documentos, como es el caso de los registros asociados a los maestres Pedro de Alango, Esteban de Irízar o Pedro de Aguirre. ${ }^{79} \mathrm{Y}$ es que el sistema de flotas limitaba el aprovechamiento de las embarcaciones y encarecía los precios de un negocio no apto para todos los bolsillos. ${ }^{80}$ Por tal motivo, el monarca podía conceder permisos para que algunos barcos navegaran en solitario o bajo ciertas condiciones privilegiadas, sobre todo si mediaban situaciones especialmente favorables para sus intereses, como el aprovechamiento de minas. ${ }^{81}$ Esto fue lo que sucedió con Simón de Tovar y Juan Mendoza de Zumelzu, que pudieron pasar 750 esclavos en naves

75 Registro de un esclavo efectuado por Clemente de Aguinaga, Sevilla, 12 de julio de 1590, ibidem, f. $137 \mathrm{v}$, f. m.

76 Registro de dos esclavas efectuado por Pedro de Sepúlveda en nombre de Antonio de Oquendo, Sevilla, 27 de abril de 1584, AGI, Contratación, 5762, 1. 7, f. 240r, f. m.

77 Registro de un esclavo efectuado por Juan Martínez de Arrazola, Sevilla, 12 de noviembre de 1573, AGI, Contratación, 5761, 1. 5, f. 187r, f. m.

78 Registro de 58 esclavos efectuado por Pedro de Murueta en el navío del maestre Zurbano, Sevilla, 30 de abril de 1588, AGI, Contratación, 5762, 1. 8, f. 96v, f. m.

79 Registro de tres esclavos efectuado por Fernando Álvarez de Soria en el navío del maestre Pedro de Alango, Sevilla, ca. 1585, AGI, Contratación, 5762, 1. 9, f. 18r, f. m.; registro de 11 esclavos «varones» efectuado por Francisco del Pesso Cañas en el navío del maestre Esteban de Irízar, Sevilla, 21 de noviembre de 1585, ibidem, f. 133r, f. m.; registro de una esclava efectuado por Juan de Uribe Apallúa en el navío del maestre Pedro de Aguirre, Sevilla, 10 de diciembre de 1585, ibidem, f. 140r, f. m.

80 Bernal Rodríguez, 2005, 376.

81 García Fuentes, 1999, 164. 
sueltas a condición de que 500 de los cautivos fueran dirigidos a Nueva Granada «para el veneficio de las minas». ${ }^{82} \mathrm{El}$ marino bilbaíno Pedro de Murueta también navegaba sus esclavos por libre: en 1583 lo hizo a bordo de un navío de aviso ${ }^{83}$ y en 1588 en un barco «suelto y sin flota». ${ }^{84} \mathrm{Si}$ en las flotas ordinarias los esclavos embarcaban en la Península y compartían espacio con las mercancías habituales de la Carrera, estos eran transportes con escala en el continente africano y reservados en exclusiva para la trata.

El trámite final del proceso administrativo era la destrucción o «rasgado» de la cédula original, que resultaba obligatorio y se efectuaba al finalizar la cuenta de registros. En estos casos, se añadía una nota informativa (la más común: «cumpliose lo que Su Magestad manda por la dicha cédula y rompiose la original» $)^{85}$ o en su defecto un escueto «cumplida». Por otra parte, aunque no era lo más habitual, también podía suceder que la cuenta quedara congelada sin llegar a completarse nunca y sin que figuren, por lo general, notas aclaratorias al respecto. ${ }^{86}$

La fase de registros es el territorio natural del cargador de esclavos. Al igual que ocurre con las concesiones o el mercado secundario, los vascos también dejan su huella en esta etapa, que se traduce en al menos 5.751 registros a Indias. ${ }^{87}$ En este caso se ha optado por acotar el análisis a los traficantes que registran más de 20 esclavos, ya que, es de suponer, muestran una mayor implicación en la trata. Dentro de estos, también hemos diferenciado entre los grandes especialistas y la gran masa de pequeños y medianos cargadores.

82 Real cédula a Simón de Tovar y Juan Mendoza de Zumelzu concediéndoles autorización para pasar 750 esclavos fuera de flota, Madrid, 8 de febrero de 1589, AGI, Indiferente, 606, 1. 1, ff. 107r-108v.

83 Registro de seis esclavos efectuado por Juan de Uribe Apallúa en un navío de Murueta, Sevilla, 6 de noviembre de 1583, AGI, Contratación, 5762, 1. 7, f. 183r, f. m.

84 Flete y condiciones establecidas entre el capitán Pedro de Murueta y el mercader Juan de Bustinza para el transporte de cuatro esclavos a las Indias, Sevilla, 11 de abril de 1588, AHPSe, Protocolos Notariales de Sevilla, 9253, ff. 465r-466r.

85 Real cédula a Francisca Ramírez concediéndole 43 licencias para pasar esclavos a las Indias, San Lorenzo, 24 de mayo de 1575, AGI, 5761, 1. 6, ff. 112r-113v, f. m.

86 Real cédula al capitán Diego de Artieda concediéndole 20 licencias para pasar esclavos a Indias, ibidem, f. 49rv.

87 Esta cuenta no incluye los esclavos pasados con licencia menuda doméstica o sin licencia de ningún tipo. Tampoco los correspondientes a la década de 1550, para la que carecemos de datos. $\mathrm{Si}$ añadimos un $10 \%$ correspondiente al contrabando que han sugerido algunos autores (Almeida Mendes, cit. en Pérez García, 2015, 832) y estimamos que, entre 1551 y 1560, los vascos registraron en torno a 1.000 esclavos — tal fue el ritmo de registros en 1541-1550 y 1561-1570 —, resultaría un total aproximado de 7.500 esclavos, cifra todavía modificable al alza. Ortiz Arza, 2019, I:198. 
TABLA 3

REGISTROS EFECTUADOS POR CARGADORES DE ORIGEN VASCO (SOLO TRAFICANTES CON AL MENOS VEINTE REGISTROS)

\begin{tabular}{|c|c|c|c|c|}
\hline \multirow[b]{3}{*}{ Cargadores } & \multicolumn{3}{|c|}{ Esclavos registrados y modalidad } & \\
\hline & \multicolumn{2}{|c|}{$\begin{array}{l}\text { Con licencias } \\
\text { propias }\end{array}$} & \multirow{2}{*}{$\begin{array}{c}\text { Con licencias } \\
\text { ajenas }\end{array}$} & \\
\hline & Concesión Real & Compradas & & Total reg. \\
\hline Pedro de Morga & 471 & 252 & 505 & 1.228 \\
\hline Juan de Urrutia & 16 & 118 & 364 & 498 \\
\hline Francisco de Zavala & 25 & 8 & 289 & 322 \\
\hline Juan de Narria & No recibió & 119 & 51 & 170 \\
\hline Pedro de Murueta & No recibió & 58 & 87 & 145 \\
\hline $\begin{array}{c}\text { TotAL } \\
\text { grandes cargadores }\end{array}$ & $\begin{array}{c}512 \\
(21,67 \%) \\
\end{array}$ & $\begin{array}{c}555 \\
(23,49 \%) \\
\end{array}$ & $\begin{array}{c}1.296 \\
(54,84 \%) \\
\end{array}$ & $\begin{array}{c}2.363 \\
(100 \%)\end{array}$ \\
\hline $\begin{array}{c}\text { RESTO } \\
\text { (27 cargadores) }\end{array}$ & $\begin{array}{c}4 \\
(0,27 \%)\end{array}$ & $\begin{array}{c}91 \\
(6,09 \%)\end{array}$ & $\begin{array}{c}1.401 \\
(93,64 \%)\end{array}$ & $\begin{array}{c}1.496 \\
(100 \%)\end{array}$ \\
\hline
\end{tabular}

Fuente: AGI, Contratación, 5760, 5761 y 5762. Elaboración propia.

Los primeros forman un grupo reducido y presentan algunos rasgos particulares. En primer lugar, disfrutan de una posición socioeconómica privilegiada que les permite acceder a las licencias en propiedad y participar activamente en las tres etapas más características del proceso. En el caso vasco, esta nómina de «campeones» de la trata la componen Pedro de Morga, Juan de Urrutia y Francisco de Zavala, que como se puede comprobar son beneficiarios, compradores de licencias y también cargadores de esclavos. Juan de Narria y Pedro de Murueta fallecieron de forma prematura, pero hasta entonces su ritmo de registros y sus actividades esclavistas fueron tan notables, incluyendo importantes incursiones en el mercado secundario, que debemos incluirlos en este grupo de aventajados. Los 2.363 registros efectuados por estas cinco personas y sus respectivos entornos ${ }^{88}$ suponen el $41,09 \%$ del total computado para la comunidad a lo largo del siglo, mientras que los 1.228 registros vinculados a Morga suman ya un 21,36 \%, cifras que sitúan al banquero vizcaíno a la cabeza de los esclavistas vascos de

88 Socios habituales de Morga fueron Jimeno de Bertendona, Juan de Arregui, Pedro de Arriarán o Andrés de Larrea, mientras que Francisco de Zavala tuvo en Nicolás de Aramburu a su más cercano compañero. 
Sevilla. En cuanto a su práctica comercial, todos poseen licencias propias que suelen destinar al más seguro mercado secundario aunque, como se puede ver, también las utilizan para efectuar registros, siendo Narria quien más se decanta por esta modalidad. Con todo, es mayoritario el recurso a la licencia cedida $(54,84 \%)$.

En un segundo grupo, mucho más amplio, de 27 cargadores, hay también nombres destacados que podríamos considerar medianos traficantes de esclavos o incluso en un futuro, en tanto que se conozcan más datos, incorporarlos a la nómina de grandes esclavistas. Es el caso del banquero Domingo de Lizarraras, que también participa, aunque en menor medida, en los tres niveles del sistema; o de Pedro de Mollinedo, Asencio de Alzola y Martín López de Isasi, que no manejan licencias propias pero sí acreditan, cada uno, más de un centenar de registros. Junto a ellos aparecen numerosos individuos de menor envergadura que tampoco suelen acceder a los lotes de licencias, bien por no ser capaces de competir con los financieros y cargadores de más renombre, o porque su interés por la trata era tan circunstancial y limitado a los registros que una cesión cumplía sobradamente con sus aspiraciones. ${ }^{89}$ En estos casos, como parece lógico, el recurso a la licencia cedida es muy elevado $(93,64 \%)$.

En cualquier caso, y al margen de la magnitud del comerciante, estos datos confirman lo que ya dejó entrever García Fuentes: «normalmente el cargador del esclavo es persona distinta al titular de la licencia». ${ }^{90}$ Las razones de esta dinámica quedarán al descubierto cuando contemos con un estudio específico sobre el mercado secundario. Lo evidente por el momento, en relación con lo ya indicado páginas atrás, es que el dominio de las licencias estaba restringido a un grupo de acomodados que trataron de rentabilizar la demanda a base de acaparar los grandes lotes, convirtiéndose así en proveedores de esta clase de títulos, sobre todo entre la gran masa de medianos y pequeños cargadores.

\section{Cruzado documental: algunos ejemplos}

Como venimos observando, los libros-registro de esclavos ofrecen una fotografía completa del sistema de licencias en sus principales vertientes: etapas, perfiles de los participantes, dinámicas, etcétera. Por otro

89 Para la lista completa de los cargadores vascos, véase Ortiz Arza, 2019, II, cuadro 3.

90 García Fuentes, 1982, 18. 
lado, tienen también algunos inconvenientes: vaguedad o arbitrariedad en el tratamiento de ciertos datos, omisiones, errores, esa llamativa laguna de información de los años cincuenta, etcétera. Además, como toda fuente administrativa, resulta demasiado esquemática, de forma que algunas cuestiones de interés quedan total o parcialmente fuera de plano. Estas últimas páginas servirán para demostrar la importancia del cruzado documental a la hora de alcanzar un mayor conocimiento sobre aquellas etapas del proceso que los libros no consiguen alumbrar. Plantearemos solo algunos ejemplos concretos, a modo aproximativo, pero el abanico de opciones podría ser mucho más amplio, siempre dependiendo de los intereses del investigador o de los objetivos del proyecto.

Si lo que se pretende rastrear son las actividades de un comerciante o compañía en particular es necesario penetrar lo máximo posible en la maraña de intereses y relaciones socioeconómicas que necesariamente condicionaba la actividad de estos negociantes y cuyos detalles es imposible conocer a través de un escueto y mecánico asiento administrativo. Muchas veces, las personas que aparecen registrando los esclavos son efectivamente los grandes nombres de la trata, pero en otras ocasiones son hombres de paja o colaboradores más o menos relevantes al servicio de sujetos mucho más poderosos que permanecen en la sombra. En esos casos, sería más apropiado hablar de «entornos comerciales» y no tanto de individuos concretos, como sucede con los registros efectuados por Jimeno de Bertendona o Juan de Arregui, traficantes de gran talla, no cabe duda, pero piezas al fin y al cabo del gran entramado de negocios levantado por Morga, tal y como demuestra la documentación notarial. ${ }^{91}$ Existen algunos registros conjuntos que ponen de manifiesto los vínculos existentes entre dos o más comerciantes, así como otros efectuados «en nombre»o «por» otra persona y que resultan también bastante esclarecedores en este sentido. Otras veces, sin embargo, son las fuentes secundarias las que proporcionan toda la información. Poco o nada conoceríamos sobre las actividades esclavistas del mercader Gregorio de Uribe-Salazar si no fuera por su expediente de pasajero, donde este alavés, natural del valle de Ayala, afirma haber contratado fletes

91 Pedro de Arriarán, en un poder otorgado para solicitar la emancipación paterna, asegura ir a Nueva España «de conpañya con los señores Pedro de Morga, y Juan de Arregui, mi hermano, e Jimeno de Bretendona», Sevilla, 22 de mayo de 1566, AHPSe, Protocolos Notariales de Sevilla, 9195, ff. $814 \mathrm{v}-815 \mathrm{r}$. En otro momento, estos apoderan a Arriarán para ejercer como factor y dirigir a la capital hispalense «el procedido de todas las cargazones de mercaderías e esclavos», Sevilla, 18 de mayo de 1566, ibidem, ff. 780v-781v. 
en la nao «San Juan Bautista» para cargar y navegar «cantidad de esclavos» valorados en «más de tres mil ducados», llevando él mismo participación directa sobre 25 de ellos. Uribe-Salazar viajó en la nave junto a los esclavos y era su consignatario en las Indias, pero su nombre no aparece en los libros de Contratación porque los registros los formalizó Pedro Díaz de Abrego, miembro, al igual que el vasco, de un entorno comercial que completaban Alonso Hernández Mantua, Simón Rodríguez Mantua y Tristán de Uribe. ${ }^{92}$

Cada registro generaba abundantes trámites documentales — poderes, fletamentos, compañías, etcétera- que podemos tratar de ubicar en los depósitos notariales a partir de los datos incluidos en los libros, como la fecha, el número de esclavos registrados, el nombre de las personas implicadas, etcétera. Estas fuentes, al igual que las judiciales, resultan mucho más dispersas y difíciles de localizar, pero pueden proporcionar gran parte de la información faltante. ${ }^{93}$ Durante las primeras semanas de 1589, por ejemplo, se anotó en los libros-registro una venta de 42 licencias que el genovés Agustín de Bivaldo acordó con el entorno formado por los vascos Bartolomé de Zuazola, Íñigo de Alzaga y Martín de Labayen, todas las cuales fueron empleadas el 6 de febrero para registrar esclavos a Tierra Firme. ${ }^{94}$ Los datos incluidos en nuestra fuente raíz nos permiten dar con la escritura notarial donde se desgranan las condiciones de la compañía suscrita entre estas personas, siendo posible descender hasta los últimos detalles. Entre otros aspectos, descubrimos que el navío empleado, de nombre La María, fue comprado a Gaspar de Espinosa por Alzaga y Luis de Aldaz, y que, llevando por maestre a Labayen y por capitán al propio Alzaga, navegó hasta Cabo Verde cargado de mercancías para emplearlas en el trueque por esclavos; o que parte de la financiación llegó a través de un crédito de 2.500 ducados otorgado por Gómez Nieto. Podemos conocer, incluso, la dieta de los cautivos, consistente en «cantidad de habas, garbanço y arros, y binagre», o el resto del utillaje adquirido para el sustento y acomodo de los mismos, desde grilletes y medicinas, hasta mantas, ollas de cobre, cucharas, etcétera. $^{95}$

92 Expediente de pasajero de Gregorio de Uribe-Salazar, ca. 1590, AGI, Contratación, 5232, n. 87, s.f.

93 Fuentes judiciales de interés son los pleitos conservados en las secciones Justicia y Escribanía del Archivo General de Indias.

94 Registros de 37 y 5 esclavos efectuados por Íñigo de Alzaga y Martín de Labayen, Sevilla, 6 de febrero de 1589, AGI, Contratación, 5762, 1. 8, f. 171r, f. m.

95 Compañía para el trato de esclavos, Sevilla, 28 de febrero de 1589, AHPSe, Protocolos Notariales de Sevilla, 9258, ff. 249r-260r. 
Los datos proporcionados por los libros-registro también facilitan el estudio del mercado de licencias. Por ejemplo, partiendo del siguiente asiento: «Tiene poder del dicho Juan de Corrales, Juan de Chagoya, para que pueda despachar y registrar çinquenta esclavos en quenta de las liçencias que aquí tiene, que pasó ante Juan Bernal de Heredia, escrivano público de Sevilla, a cinco de diziembre de ochenta y ocho»..$^{96}$

Podemos acudir a los protocolos del escribano indicado y tratar de localizar el documento al que hace referencia, siempre con más facilidad si perduran en buen estado los índices originales. En este y otros casos parecidos es posible conocer el precio por el que se vendieron las licencias: «os e bendido e bendo cada una de las dichas liçençias de esclavos a preçio de a quinze ducados». ${ }^{97}$

Otro aspecto que ha planteado dudas a los investigadores es la necesidad de diferenciar entre licencias «gruesas» o comerciales, que son las recogidas en nuestra fuente, $\mathrm{y}$ «menudas» $\mathrm{O}$ «de a dos ducados», que facultan a quien las recibe para pasar esclavos domésticos a las Indias. Enriqueta Vila no ve una pauta clara a la hora de otorgar las licencias, ya que a su juicio se mezclan «los asientos de partidas cuantiosas con concesiones de pequeñas cantidades». ${ }^{98}$ En la misma dirección apunta Lutgardo García, que considera «difícil distinguir qué licencias se concedieron para servicios personales y cuáles iban destinadas al mercado esclavista». ${ }^{99}$ Las diferencias tienen que ver sobre todo con la propia naturaleza de la concesión; si las gruesas eran el elemento central de la trata española y buscaban estimular el comercio, tanto de la propia licencia como del esclavo, las menudas eran por lo general intransferibles y prohibían expresamente la venta del cautivo, llegándose al punto de exigir la identificación física del mismo o que el supuesto propietario lo acompañase en el viaje ultramarino. ${ }^{100}$ Las cuestiones fiscales tampoco dan lugar a confusión, ya que si las tasas de

96 Asiento sobre el traspaso de 50 licencias de Juan de Corrales a Juan de Echagoya, Sevilla, ca. 1588, AGI, Contratación, 5672, 1. 8, f. 189v.

97 Juan de Corrales vende a Juan de Echagoya 50 licencias para pasar esclavos a las Indias, Sevilla, 5 de diciembre de 1588, AHPSe, Protocolos Notariales de Sevilla, 14357, ff. 282r-284r.

98 Vila Vilar, 1985, 259.

99 García Fuentes, 1982, 8.

100 Real cédula a los oficiales de la Contratación para que permitan pasar a La Española seis esclavos cristianos que Juan Ponce de León envía a su hijo, con la condición de no poderlos «vender, ni enagenar, sino servirse de ellos», Logroño, 28 de septiembre de 1512, AGI, Indiferente, 419, 1. 4, f. 27r. Real cédula a Juan Guillarte concediéndole licencia para pasar un esclavo de «servicio de vuestra persona y casa, yendo vos en persona a las dichas Indias y no de otra manera», Valladolid, 14 de julio de 1551, AGI, Indiferente, 424, 1. 22, ff. 319v-320r. 
las licencias gruesas no dejaron de crecer hasta situarse en los 30 ducados la unidad, por una licencia menuda nunca se pagaron más de dos ducados. La principal pega, ciertamente, es la dispersión de los datos; se echa en falta una herramienta de control que recopile las concesiones de carácter doméstico de la misma forma que sucede con las comerciales. En su lugar pueden resultar de ayuda las fuentes contables, como los libros de cargo y data donde los oficiales del monarca administraban, entre otros aspectos, la recaudación de los derechos provenientes de las licencias de esclavos. Especialmente útil resulta el material de Ochoa de Luyando, ya que este secretario tenía por costumbre abrir dos hojas separadas para anotar los cobros correspondientes a cada tipo de concesión, utilizando además la terminología que aquí recogemos y que resulta bastante aclaratoria. ${ }^{101}$ No obstante, para mayor seguridad, es posible acudir a los cedularios y recopilaciones diplomáticas donde se pueden localizar los documentos vinculados a cada concesión. Por ejemplo, si Luyando anota cuatro ducados a nombre de Juan Rodríguez Mondragón por razón de dos licencias, ${ }^{102}$ la escritura resultante confirma que se trata de esclavos domésticos: «Podáis pasar y paséis a las nuestras Indias y islas y Tierra Firme del mar océano, una esclava negra nonbrada María con una hija suya de hedad de diez años poco más o menos, siendo anbas negras y no mulatas ni de las prohibidas, a pasar a aquellas partes para servicio de vuestra persona y casa, yendo vos en persona a las dichas Indias e no de otra manera». ${ }^{103}$

Otra variante de trabajo nos llevaría a estudiar la posible existencia de un circuito redistribuidor que vincule el mercado local hispalense con la trata atlántica de esclavos, por ejemplo cotejando los registros de Contratación con las numerosas compraventas conservadas en los fondos notariales de Sevilla. De este modo, si en enero de 1545 localizamos al guipuzcoano Esteban de Aguinaga vendiendo tres esclavos y una esclava a Pedro Sáez de Ibarburen, ${ }^{104}$ en mayo aparece un Pedro Sáez de «Ibarburu» registrando cuatro esclavos, tres hombres y una mujer, en la nao del maestre Íñigo de

101 Libro de cargo y data de los receptores Hernando Ochoa y Ochoa de Luyando, 1528-1571, AGI, Contratación, 36.

102 Asiento sobre el pago de derechos por licencias de esclavos de Juan Rodríguez Mondragón, 1555 , ibidem, n. 3, f. 620r.

103 Real cédula a Juan Rodríguez Mondragón concediéndole licencia para pasar dos esclavas de servicio a las Indias, Valladolid, 3 de agosto de 1555, AGI, Indiferente, 425, 1. 23, ff. 168v-169r.

104 Esteban de Aguinaga vende tres esclavos y una esclava de origen guineano a Pedro Sáez de Ibarburen, Sevilla, 16 de enero de 1545, AHPSe, Protocolos Notariales de Sevilla, 12317, f. [239v-240v]. 
Ibartola, con mucha probabilidad los mismos individuos recogidos en el documento anterior. ${ }^{105}$

Finalizamos con otro aspecto que puede resultar interesante, como son los rendimientos de la trata. Esta línea de investigación no resulta nada sencilla, pero nos llevaría a buscar la correlación entre los registros de las remesas embarcadas en las flotas de vuelta y los libros de esclavos que venimos analizando. ${ }^{106}$ En el expediente de difunto de Domingo de Bilbao la Vieja, por ejemplo, encontramos información sobre una remesa consignada en Sevilla a su tío Andrés de Larrea: «setenta y quatro planchas, las chicas y grandes, que pesan çíento y veynte y çinco marcos». La mitad de la plata, según se indica, va «por quenta de la quarta parte de las dozientas y treinta y dos piezas de esclavos venidos en el navío de Antón Sánchez de Armas». ${ }^{107}$ Acudiendo a los libros de Contratación localizamos, efectivamente, el registro de 232 esclavos efectuado el año anterior, el 5 de mayo de 1564, por Pedro de Morga, Juan de Arregui, Jimeno de Bertendona, Lope Fernández y el propio Larrea. ${ }^{108}$

\section{Conclusión}

Recordando los puntos clave del sistema de licencias, vemos cómo la real cédula era el tipo documental que servía para conceder los lotes de licencias gruesas o comerciales que facultaban a un cargador para registrar esclavos a las Indias, siendo el registro el acto administrativo de canjear esas licencias a cambio de adscribir una remesa a un navío y maestre determinados. Entre medias, las licencias circulaban por los mercados a través de traspasos y cesiones, en un proceso especulativo que provocaba, habitualmente, una fragmentación de los lotes y su reparto entre una multitud de pequeños o medianos cargadores. Los libros-registro de esclavos son el

105 Registro de tres esclavos y una esclava efectuado por Pedro Sáez de «Ibarburu», Sevilla, 13 de mayo de 1545, AGI, Contratación, 5760, 1. 3, f. 215.

106 En el Archivo General de Indias, la información sobre las remesas de vuelta puede encontrarse en la serie «Registros de venida» o en la documentación inserta en pleitos judiciales, expedientes de difuntos, etcétera.

107 Registro de vuelta (fragmento) de la nao San Bartolomé contenido en el expediente de difunto de Domingo de Bilbao la Vieja, 1565, AGI, Contratación, 203, n. 4, r. 3, s. f.

108 Registro de 232 esclavos efectuado por Pedro de Morga, Juan de Arregui, Jimeno de Bertendona, Lope Fernández y Andrés de Larrea, Sevilla, 5 de mayo de 1564, AGI, Contratación, 5761, 1. 4 , f. 104 r, f. m. 
reflejo administrativo de todo este proceso y contribuyen a la investigación de varias formas:

- En primer lugar, agrupan y relacionan varios de los conceptos esenciales que, a grandes rasgos, acabamos de resumir. Su principal valor, en este sentido, es que vinculan cada cédula de concesión de licencias con sus correspondientes cuentas de registros, siendo así una de las fuentes que mejor pueden ayudar a cuantificar la trata con Hispanoamérica del siglo XVI, tanto a nivel de comunidades o «naciones» mercantiles concretas, como desde una perspectiva más amplia.

- Al mismo tiempo, gracias a su estructura, proporcionan una visión panorámica del sistema de licencias en sus principales etapas (concesión, mercado secundario y registro), permiten diferenciar los perfiles de los participantes en el proceso (beneficiarios, compradores de licencias y cargadores) y ponen de manifiesto los intereses o pautas de actuación de cada cual en el escenario de la trata.

Por otro lado, la aproximación efectuada a través del caso vasco nos ha permitido reconocer una serie de dinámicas recurrentes que posiblemente sean extrapolables al ámbito general. La práctica más habitual nos muestra a un beneficiario ajeno a la trata que recibe un lote de licencias a modo de merced y lo traspasa, tan pronto como puede, a un comerciante y/o distribuidor de vocación financiera que, a su vez, va cediendo los títulos, generalmente en menudeo, a los cargadores de esclavos. De este modo, resulta coherente que la mayor parte de los traficantes efectúe sus registros por medio de cesiones, circunstancia ligada a dinámicas internas del mercado secundario y más precisamente a la acumulación de licencias en manos de ricos distribuidores, que pueden ser los grandes cargadores de esclavos o comerciantes especializados en esta fase concreta del proceso.

Por último, el potencial de nuestra fuente raíz se ve lastrado por dos inconvenientes principales: la pérdida de los registros correspondientes a la década de 1550 y la excesiva concisión o vaguedad de los datos recogidos. En consecuencia, resulta imprescindible completar y relacionar su información con otras fuentes de carácter notarial, judicial o administrativo, todo ello con objeto de definir conceptos, rellenar vacíos y buscar las piezas de encaje entre esta etapa más abstracta o burocrática de la trata y su posterior proyección atlántica.

Recibido, 12 de febrero de 2020

Segunda versión, 13 de junio de 2020

Aceptado, 1 de julio de 2020 


\section{Referencias bibliográficas}

Angulo Morales, Alberto, «Mercados y financieros vascos: el circuito de la plata y su control en el seiscientos», en García Fernández, Ernesto y Vítores Casado, Imanol (eds.), Tesoreros, arrendadores y financieros en los reinos hispánicos: la Corona de Castilla y el Reino de Navarra (s. XIV-XVII), Málaga, Instituto de Estudios Fiscales, 2012, 241-256.

Arriaga Mesa, Marcos, «Un acercamiento al comportamiento del precio de los esclavos en La Habana en la segunda mitad del siglo XVI», Anuario de Estudios Americanos, 56:1, Madrid, 1999, 15-39.

Bernal Rodríguez, Antonio Miguel, España, proyecto inacabado, Madrid, Marcial Pons, 2005.

Borucki, Alex; Eltis, David y Wheat, David, «Atlantic History and the Slave Trade to Spanish America», The American Historical Review, 120, Oxford, 2015, 433-461.

Carande y Thovar, Ramón, Carlos V y sus banqueros, 2 vols., Barcelona, Crítica, 1983 [1. ${ }^{\mathrm{a}}$ ed. 1967].

Crailsheim, Eberhard, The Spanish Connection: French and Flemish Merchants Networks in Seville (1570-1650), Colonia, Böhlau-Verlag, 2016.

Díaz de Durana Ortiz de Urbina, José Ramón y Otazu Llana, Alfonso de, El espíritu emprendedor de los vascos, Madrid, Sílex, 2008.

Díaz Soler, Luis, Historia de la esclavitud negra en Puerto Rico, San Juan, Universidad de Puerto Rico, 1970 [1. ${ }^{\mathrm{a}}$ ed. 1953].

Donoso Anes, Rafael, «Algunos aspectos relacionados con el control administrativo y contable de los esclavos enviados a Hispanoamérica (hasta el final del período de las licencias en 1595)», Revista española de financiación y contabilidad, 110, Madrid, 2001, 1093-1135.

Eagle, Marc, «The Early Slave Trade to Spanish America. Caribbean Pathways, 1530-1580», en Altman, Ida; Wheat, David, The Spanish Caribbean \& the Atlantic World in the Long Sixteenth Century, Lincoln, University of Nebraska, 2019, 139-162.

Eagle, Marc y Wheat, David, «The Early Iberian Slave Trade to the Spanish Caribbean», en Borucki, Alex; Eltis, David y Wheat, David (eds.), From the Galleons to the Highlands. Slave Trade Routes to the Spanish America, Albuquerque, University of New Mexico, 2020, 47-72.

Fernández Chaves, Manuel Francisco y Pérez García, Rafael Mauricio, «Las redes de la trata negrera: mercaderes portugueses y tráfico de esclavos en Sevilla (c. 1560-1580)», en Martín Casares, Aurelia y García Barranco, Margarita (coords.), La esclavitud negroafricana en la Historia de España. Siglos XVI y XVII, Granada, Comares, 2011, 5-34.

Fernández Chaves, Manuel Francisco, «La consolidación del capitalismo portugués en Sevilla. Auge, caída y resurgir político del mercader Bento Váez, 
1550-1580», en Iglesias Rodríguez, Juan José; García Bernal, Jaime y Díaz Blanco, José Manuel (eds.), Andalucía en el mundo atlántico moderno. Ciudades y redes, Madrid, Sílex, 2018, 183-238.

Fernández Martín, Luis, El almirante Luis Colón y su familia en Valladolid (15541611), Valladolid, Casa Museo de Colón, 1986.

García Fuentes, Lutgardo, «Licencias para la introducción de esclavos en Indias y envíos desde Sevilla en el siglo XVI», Anuario de Historia de América Latina, 19, Hamburgo, 1982, 1-46.

García Fuentes, Lutgardo, «La introducción de esclavos en Indias desde Sevilla en el siglo XVI», en Torres Ramírez, Bibiano y Hernández Palomo, José (coords.), Andalucía y América en el siglo XVI. Actas de las III Jornadas de Andalucía y América, v. 1, Sevilla, Escuela de Estudios Hispano-Americanos, CSIC, 1983, 249-274.

García Fuentes, Lutgardo, «El comercio trasatlántico», en Ramos Pérez, Demetrio (coord.), La formación de las sociedades iberoamericanas (1568-1700), Madrid, Espasa, 1999, 151-178.

Lapeyre, Henry, «Le trafic négrier avec l'Amérique Espagnole», en Homenaje a Jaime Vicens Vives, v. 2, Barcelona, Universidad de Barcelona, 1967, 285-306.

Lorenzo Sanz, Eufemio, Comercio de España con América en la época de Felipe II, 2 vols., Valladolid, Universidad de Valladolid, 1979.

Lucena Salmoral, Manuel, Regulación de la esclavitud negra en las colonias de América Española (1503-1886): Documentos para su estudio, Madrid, Universidad de Alcalá de Henares/Universidad de Murcia, 2005.

Mateus Ventura, María da Graça, Negreiros portugueses na rota das Índias de Castela: 1541-1556, Lisboa, Edições Colibri/Instituto de Cultura Ibero-Atlântica, 1999.

Mellafe, Rolando, Breve historia de la esclavitud negra en América Latina, México D. F., Secretaría de Educación Pública, 1973.

Mira Caballos, Esteban, «Las licencias de esclavos negros a Hispanoamérica», Revista de Indias, 54:201, Madrid, 1994, 273-298.

Ortiz Arza, Javier, La comunidad vasca de Sevilla y la trata de esclavos (s. XVI), tesis doctoral dirigida por José Ramón Díaz de Durana Ortiz de Urbina y Manuel Francisco Fernández Chaves, Departamento de Historia Medieval, Moderna y de América, Universidad del País Vasco/Euskal Herriko Unibertsitatea, 2019.

Otte, Enrique, «Los mercaderes vizcaínos Sancho Ortiz de Urrutia y Juan de Urrutia», Boletín Histórico, 6 (separata), Caracas, 1964, 1-32.

Pérez García, Rafael Mauricio y Fernández Chaves, Manuel Francisco, «Sevilla y la trata negrera atlántica: envío de esclavos desde Cabo Verde a la América española», en Álvarez Santaló, León Carlos (coord.), Estudios de Historia 
Moderna en homenaje al profesor Antonio García-Baquero, Sevilla, Universidad de Sevilla, 2009, 597-622.

Pérez García, Rafael Mauricio, «Metodología para la cuantificación y el análisis de la trata de esclavos hacia la América española en el siglo XVI», en Rey Castelao, Ofelia y Suárez Golán, Fernando (eds.), Los vestidos de Clío. Métodos y tendencias recientes de la historiografía modernista española (19732013), Santiago de Compostela, Universidad de Santiago de Compostela, 2015, 823-840.

Ramos Pérez, Demetrio, «El negocio negrero de los Welser y sus habilidades monopolistas», Revista de Historia de América, 81, La Habana, 1976, 7-81.

Recopilación de Leyes de los Reynos de las Indias mandadas imprimir, y publicar por la magestad católica del rey don Carlos II, 4 tomos, Madrid, Boix, 1841 [1. ${ }^{\mathrm{a}}$ ed. 1681].

Saco y López-Cisneros, José Antonio, Historia de la esclavitud de la raza africana en el Nuevo Mundo y en especial en los países Américo-Hispanos, 4 vols., Barcelona, Imprenta de Jaime Jepús, 1879.

Vila Vilar, Enriqueta, «La esclavitud en el Caribe, Florida y Luisiana: algunos datos generales para su estudio», en Antonio Acosta y Juan Marchena (eds.), La influencia de España en el Caribe, Florida y la Luisiana (1500-1800), Madrid, Instituto de Cooperación Iberoamericana, 1983, 223-242.

Vila Vilar, Enriqueta, «Posibilidades y perspectivas para el estudio de la esclavitud en los fondos del Archivo General de Indias», Archivo Hispalense, 207-208, Sevilla, 1985, 255-272.

Vila Vilar, Enriqueta, Hispanoamérica y el comercio de esclavos. Los asientos portugueses, Sevilla, Universidad de Sevilla, 2014 [1. a ed. 1977]. 